\title{
Residual Microvascular Risk in Type 2 Diabetes in 2014: Is it Time for a Re- Think? A Perspective from the Residual Risk Reduction Initiative (R3i)
}

Michel P Hermans ${ }^{1 *}$, Jean-Charles Fruchart ${ }^{2}$, Jean Davignon ${ }^{3}$, Khalid Al-Rubeaan ${ }^{4}$, Pierre Amarenco ${ }^{5}$, Gerd Assmann ${ }^{6}$, Philip Barter $^{7}$, John Betteridge $^{8}$, Eric Bruckert ${ }^{9}$, M John Chapman ${ }^{10}$, Ada Cuevas ${ }^{11}$, Michel Farnier ${ }^{12}$, Ele Ferrannini ${ }^{13}$, Paola Fioretto ${ }^{14}$, Jacques Genest ${ }^{15}$, Henry N Ginsberg ${ }^{16}$, Antonio M Gotto $\mathrm{Jr}^{17}$, Dayi Hu ${ }^{18}$, Takashi Kadowaki ${ }^{19}$, Tatsuhiko Kodama ${ }^{20}$, Michel Krempf ${ }^{21}$, Yuji Matsuzawa ${ }^{22}$, Jesús Millán Núñez-Cortés ${ }^{23}$, Carlos Calvo Monfil ${ }^{24}$, Hisao Ogawa ${ }^{25}$, Jorge Plutzky ${ }^{26}$, Daniel J Rader ${ }^{27}$, Željko Reiner ${ }^{28}$, Shaukat Sadikot ${ }^{29}$, Raul D Santos ${ }^{30}$, Evgeny Shlyakhto ${ }^{31}$, Piyamitr Sritara ${ }^{32}$, Rody Sy ${ }^{33}$, Alan Tall ${ }^{34}$, Chee-Eng Tan ${ }^{35}$, Lale Tokgözoğlu ${ }^{36}$, Peter P Toth ${ }^{37}$, Paul Valensi ${ }^{38}$, Christoph Wanner ${ }^{39}$, Alberto Zambon ${ }^{14}$, JunRen Zhu ${ }^{40}$ and Paul Zimmet ${ }^{41}$

${ }^{1}$ Clinical university St-luc, Brussels, Belgium

${ }^{2} R^{3} i$ Foundation, St. Alban-Anlage 46, Basel, Switzerland

${ }^{3}$ Clinical Research Institute of Montreal Montreal University Health Center and Department of Experimental Medicine, McGill University, Montreal, Canada

${ }^{4}$ University Diabetes Center, King Saud University, Riyadh, Saudi Arabia

${ }^{5}$ Department of Neurology and Stroke Centre, Bichat University Hospital, Paris, France

${ }^{6}$ Assmann Foundation for Prevention, Germany

${ }^{7}$ Centre for Vascular Research, University of New South Wales, Sydney, Australia

${ }^{8}$ University College London, London, UK

${ }^{9}$ Endocrinology and Cardiovascular Disease Prevention, Hospital Pitié-Salpêtrière, Paris, France

${ }^{10}$ University of Pierre and Marie Curie, INSERM Dyslipidemia and Atherosclerosis Research Unit, Hospital Pitié-Salpêtrière, Paris, France

${ }^{11}$ Nutrition Center, Clínica Las Condes, Santiago, Chile

${ }^{12}$ Point Medical, Dijon, France

${ }^{13}$ University of Pisa School of Medicine, and Metabolism Unit of the National Research Council (CNR) Institute of Clinical Physiology, Pisa, Italy

${ }^{14}$ Department of Medical and Surgical Sciences, University of Padova, Padova, Italy

${ }^{15}$ McGill University and Center for Innovative Medicine, McGill University Health Center/Royal Victoria Hospital, Montreal, Canada

${ }^{16}$ Department of Medicine and Irving Institute for Clinical and Translational Research, Columbia University, New York, USA

${ }^{17}$ Weill Cornell Medical College, Cornell University, New York, USA

${ }^{18}$ Hospital of Peking University, Beijing, China

${ }^{19}$ Diabetes and Metabolic Diseases Unit, University of Tokyo, Japan

${ }^{20}$ Department of Systems Biology and Medicine, University of Tokyo, Japan

${ }^{21}$ Human Nutritional Research Center and Department of Endocrinology, Metabolic diseases and Nutrition, University Hospital Nantes, Nantes, France

${ }^{22}$ Sumitomo Hospital and Osaka University, Osaka, Japan

${ }^{23}$ University Hospital Gregorio Marañón, Madrid, Spain

${ }^{24}$ University of Concepción, Concepción, Chile

${ }^{25}$ Department of Cardiovascular Medicine, Kumamoto University, Kumamoto, and National Cerebral and Cardiovascular Center, Osaka, Japan

${ }^{26}$ Brigham and Women's Hospital and Harvard Medical School, Boston, USA

${ }^{27}$ Division of Translational Medicine and Human Genetics, Smilow Center for Translational Research, Penn Cardiovascular Institute, Philadelphia, Pennsylvania, USA

${ }^{28}$ Department of Internal Medicine, University Hospital Center Zagreb, School of Medicine, University of Zagreb, Croatia

${ }^{29}$ Jaslok Hospital and Research Center, Mumbai, India

${ }^{30}$ Director of Clinical Unit of Lipids InCor- HCFMUSP, Sao Paulo, Brazil

${ }^{31}$ Federal Almazov Heart Blood Endocrinology Centre, St Petersburg, Russia

${ }^{32}$ Mahidol University, Bangkok, Thailand

${ }^{3}$ University of the Philippines-Philippine General Hospital, Manila, The Philippines

${ }^{34}$ Specialized Center of Research (SCOR) in Molecular Medicine and Atherosclerosis, Columbia University, College of Physicians \& Surgeons, New York, USA

${ }^{35}$ Gleneagles Medical Centre, Singapore

${ }^{36}$ Hacettepe University, Ankara, Turkey

${ }^{37} \mathrm{CGH}$ Medical Center, Sterling, Illinois, and University of Illinois School of Medicine, Peoria, Illinois

${ }^{38}$ Hospital Jean Verdier, Department of Endocrinology Diabetology Nutrition, AP-HP, Paris-Nord University, CRNH-IdF, CINFO, Bondy, France

${ }^{39}$ University Hospital Würzburg, Würzburg, Germany

${ }^{40}$ Zhongshan Hospital, Fudan University, Shanghai, China

${ }^{41}$ Baker IDI Heart and Diabetes Institute, Melbourne, Australia

\begin{abstract}
Microvascular complications associated with type 2 diabetes, including diabetic retinopathy, nephropathy and neuropathy, account for much of the societal burden of diabetes. Even with effective multifactorial intervention, targeting glycemia, blood pressure and lowdensity lipoprotein cholesterol, in addition to lifestyle intervention, a high residual microvascular risk persists. The Residual Risk Reduction Initiative $\left(\mathrm{R}^{3} \mathrm{i}\right)$ highlights two key priorities for reducing this residual risk. First, there should be optimal management of cardiometabolic risk factors, including atherogenic dyslipidemia, elevated triglycerides and low plasma high-density lipoprotein cholesterol, to improve lipid goal attainment. Second, consistent evidence from two major trials may merit consideration of adjunctive fenofibrate therapy to slow progression of diabetic retinopathy in type 2 diabetes patients with pre-existing disease. These data provide a strong rationale for testing in a prospective study. The $\mathrm{R}^{3} \mathrm{i}$ strongly believes that addressing both priorities is critical to reducing the substantial residual risk of microvascular complications in type 2 diabetes.
\end{abstract}

Keywords: Microvascular residual risk; Type 2 diabetes; Diabetic retinopathy; Diabetic nephropathy; Atherogenic dyslipidemia; Prevention; Guidelines

*Corresponding author: Michel P Hermans, MD PhD Dip Nat Sci Dip Earth Sci Dip Geog Env PG Cert (SocSc), Endocrinology \& Nutrition, UCL 54. 74 Tou Claude Bernard +1, avenue Hippocrate 54, B 1200 Brussels, Belgium, Tel: +32 27645475; Fax: +32 27645418; E-mail: michel.hermans@uclouvain.be

Received July 22, 2014; Accepted August 11, 2014; Published August 19, 2014 Citation: Hermans MP, Fruchart JC, Davignon J, Al-Rubeaan K, Amarenco P et al. (2014) Residual Microvascular Risk in Type 2 Diabetes in 2014: Is it Time for a Re-Think? A Perspective from the Residual Risk Reduction Initiative (R3i). J Diabetes Metab 5: 413 doi:10.4172/2155-6156.1000413

Copyright: (C) 2014 Hermans MP, et al. This is an open-access article distributed under the terms of the Creative Commons Attribution License, which permits unrestricted use, distribution, and reproduction in any medium, provided the original author and source are credited. 
Citation: Hermans MP, Fruchart JC, Davignon J, Al-Rubeaan K, Amarenco P, et al. (2014) Residual Microvascular Risk in Type 2 Diabetes in 2014: Is it Time for a Re-Think? A Perspective from the Residual Risk Reduction Initiative (R3i). J Diabetes Metab 5: 413 doi:10.4172/21556156.1000413

Page 2 of 8

\section{Introduction}

Diabetes mellitus poses one of the most important health challenges in the $21^{\text {st }}$ century. Based on latest estimates, globally more than 382 million people have diabetes, predominantly type 2 diabetes, and by 2035 this will have risen to 592 million [1]. The greatest escalation in diabetes prevalence has been in developing regions, and as a consequence, it is anticipated that the future burden of diabetes will be greatest there [1].

Much of the focus of clinical management in type 2 diabetes has been on prevention of cardiovascular complications from macroangiopathies. However, recent data from the Global Burden of Disease 2010 highlight the importance of diabetes-related microvascular complications, including diabetic retinopathy and nephropathy, responsible for more than $50 \%$ of the burden of disability associated with diabetes [2]. About one in three people with type 2 diabetes have clinical signs of diabetic retinopathy or diabetic kidney disease, and an even larger proportion has silent or clinical peripheral (lower-limb) sensory neuropathy $[1,3,4]$. Indeed, diabetic retinopathy is the leading cause of vision loss in adults of working age (20 to 65 years) in industrialized countries [1]. Although the cost of managing such complications is initially relatively low (especially when compared with the diagnostic and therapeutic costs of macroangiopathies), progression to more advanced stages, i.e., visual loss, end-stage renal disease and lower-extremity amputation substantially increases this. Estimates suggest that the presence of microvascular complications almost doubles management costs compared with patients without these complications [5]. Together, the escalation in diabetes prevalence and increasing longevity of people with diabetes due to improved management of cardiometabolic risk factors, will undoubtedly contribute to a further substantial increase in the socioeconomic burden associated with chronic diabetes-related microvascular complications [6]. As an example from the US, costs associated with managing diabetes-related complications have nearly doubled over the last 5 years, despite improvements in general care. Given finite healthcare resources, this is an urgent issue warranting action [7].
Effective multifactorial intervention, targeting glycaemia, blood pressure and Low-Density Lipoprotein (LDL) cholesterol, is clearly important for preventing or delaying progression of macro- and microvascular complications. Yet even with optimal management, such complications continue to develop or progress. Five years ago, the Residual Risk Reduction Initiative $\left(\mathrm{R}^{3} \mathrm{i}\right)$ highlighted this issue, clearly illustrated by the STENO-2 study [8-10]. Multifactorial intervention, including tight glycemic regulation, blood pressure control and the use of renin-angiotensin system blockers, aspirin and statins, in addition to lifestyle intervention, reduced the risk of macroangiopathies and major diabetes-related complications (retinopathy and nephropathy), but was insufficient to completely prevent the development or progression of microvascular disease in up to $50 \%$ of patients with type 2 diabetes (Figure 1) $[9,10]$. While it is acknowledged that few patients achieved all three targets for blood glucose, blood pressure and LDL cholesterol, STENO-2 still showed the high residual risk of microvascular complications that persists in diabetes patients.

\section{Residual microvascular risk: an update}

Subsequent investigations focused on a key question: Does intensification of glycemic or blood pressure control reduce this high residual risk of diabetes-related microvascular complications? The rationale for such approaches was suggested by data from the United Kingdom Prospective Diabetes Study (UKPDS), which showed improved benefit, especially for retinopathy, with prolonged improvement in glycemic control in newly-diagnosed type 2 diabetes patients (Table 1) [11,12].

With respect to improved glycemic control, the Action to Control Cardiovascular Risk-Eye (ACCORD-Eye) study showed that targeting euglycemia (i.e. $\mathrm{HbA}_{1 \mathrm{c}}<6 \%[42 \mathrm{mmol} / \mathrm{mol}]$ as a surrogate marker) in persons with long-standing type 2 diabetes significantly slowed the progression of diabetic retinopathy, defined by $\geq 3$ steps worsening of the Early Treatment Diabetic Retinopathy Study (ETDRS) scale, or the development of proliferative retinopathy requiring laser treatment or vitrectomy (absolute reduction from $10.4 \%$ to $7.3 \%$, relative risk



Observation period (13.3 years)

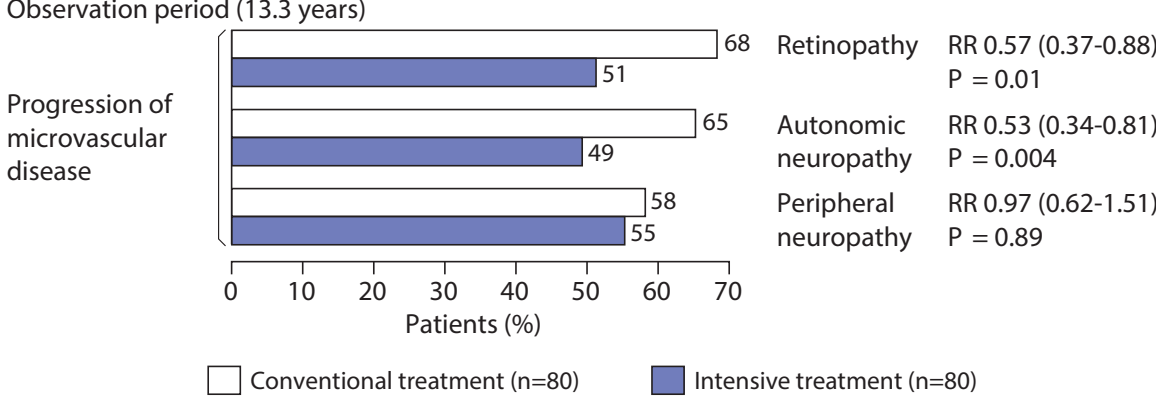

Figure 1: As highlighted by the R3i, the STENO-2 study showed that intensive multifactorial intervention delayed but did not prevent the development or progression of diabetic-related microvascular complications in persons with type 2 diabetes. Data presented as relative risk (RR) with $95 \%$ confidence intervals. Reproduced with permission from Fruchart JC et al. [8] RR relative risk. Diabetic nephropathy was defined as urinary albumin excretion of $>300$ mg per 24 hours in 2 of 3 sterile urine specimens. Diabetic retinopathy was graded according to the 6-level grading scale of the European Community-funded Concerted Action Programme into the Epidemiology and Prevention of Diabetes by 2 independent ophthalmologists, who were unaware of treatment assignment. Peripheral neuropathy was measured with a biothesiometer and autonomic neuropathy was diagnosed based on measurement of the RR interval on an ECG during paced breathing and an orthostatichypotension test conducted by a laboratory technician who was unaware of the patients' treatment assignment.

\section{Nephropathy RR $0.39(0.17-0.87)$ $P=0.003$ \\ RR $0.42(0.21-0.86)$ $P=0.02$}


Citation: Hermans MP, Fruchart JC, Davignon J, Al-Rubeaan K, Amarenco P, et al. (2014) Residual Microvascular Risk in Type 2 Diabetes in 2014 Is it Time for a Re-Think? A Perspective from the Residual Risk Reduction Initiative (R3i). J Diabetes Metab 5: 413 doi:10.4172/21556156.1000413

Page 3 of 8

\begin{tabular}{|c|c|c|c|c|c|c|c|}
\hline $\begin{array}{l}\text { Trial } \\
\text { [follow-up] }\end{array}$ & $\mathbf{N}$ & Intervention & Outcome measure & $\begin{array}{l}\text { Relative } \\
\text { RR }\end{array}$ & $\begin{array}{l}\text { Absolute } \\
\text { RR }\end{array}$ & NNT & p-value \\
\hline \multicolumn{8}{|l|}{ Diabetic retinopathy } \\
\hline \multirow[t]{2}{*}{ ACCORD-EYE [13] [4 years] } & 2,856 & Intensive vs. standard glycemic control & \multirow{2}{*}{$\begin{array}{l}\text { Progression } \geq 3 \text { steps of ETDRS, laser } \\
\text { photocoagulation or vitrectomy }\end{array}$} & $37 \%$ & $3.1 \%$ & 32 & 0.003 \\
\hline & 1,263 & Intensive vs. standard BP control & & $23 \%$ & $-1.6 \%$ & -62 & 0.29 \\
\hline ADVANCE $[15,19]$ [5 years] & 11,140 & Intensive glycemic control & New or worsening retinopathy & $5 \%$ & $0.3 \%$ & 333 & NR \\
\hline [4.3 years] & & Intensive vs. standard BP control & & $1 \%$ & $-0.1 \%$ & -100 & NR \\
\hline VADT (14) [5.6 years] & 1,791 & Intensive vs. standard glycemic control & Progression $\geq 2$ steps of ETDRS & $23 \%$ & $5.1 \%$ & 19 & 0.07 \\
\hline \multirow[t]{2}{*}{$\begin{array}{l}\text { UKPDS* }[11,12] \\
\text { [Up to } 12 \text { years] }\end{array}$} & 3,867 & Intensive vs. standard glycemic control & $\begin{array}{l}\text { 2-step progression of ETDRS } \\
\text { Retinal photocoagulation }\end{array}$ & $\begin{array}{l}21 \% \\
29 \%\end{array}$ & $\begin{array}{l}10.1 \% \\
2.7 \%\end{array}$ & $\begin{array}{l}10 \\
37\end{array}$ & $\begin{array}{l}0.015 \\
0.003\end{array}$ \\
\hline & 1,148 & Intensive vs. standard BP control & $\begin{array}{l}\text { 2-step progression of ETDRS } \\
\text { Retinal photocoagulation }\end{array}$ & $\begin{array}{l}34 \% \\
35 \%\end{array}$ & $\begin{array}{l}17.3 \% \\
4.0 \%\end{array}$ & $\begin{array}{c}6 \\
25\end{array}$ & $\begin{array}{c}0.0038 \\
0.023\end{array}$ \\
\hline
\end{tabular}

Table 1: Effect of intensification of glucose or blood pressure control on progression of diabetic microvascular complications in type 2 diabetes patients.

\begin{tabular}{|c|c|c|c|c|c|c|c|}
\hline Trial & $\mathrm{N}$ & Intervention & Outcome measure & Relative RR & Absolute RR & NNT & $p$-value \\
\hline \multicolumn{8}{|l|}{ Renal outcomes } \\
\hline $\begin{array}{l}\text { ACCORD }[16] \\
{[5 \text { years }]}\end{array}$ & 10,251 & Intensive vs. standard glycemic control & $\begin{array}{l}\text { New-onset microalbuminuria } \\
\text { New-onset macroalbuminuria }\end{array}$ & $\begin{array}{l}15 \% \\
29 \%\end{array}$ & $\begin{array}{l}3.1 \% \\
1.7 \%\end{array}$ & $\begin{array}{l}32 \\
58\end{array}$ & $\begin{array}{l}0.0012 \\
0.0003\end{array}$ \\
\hline $\begin{array}{l}\text { ADVANCE }[15,19] \\
{[5 \text { years] }}\end{array}$ & 11,140 & Intensive vs. standard glycemic control & $\begin{array}{l}\text { New or worsening nephropathy } \\
\text { New onset microalbuminuria }\end{array}$ & $\begin{array}{l}21 \% \\
9 \%\end{array}$ & $\begin{array}{l}1.1 \% \\
2.0 \%\end{array}$ & $\begin{array}{l}91 \\
50\end{array}$ & $\begin{array}{l}0.006 \\
0.02\end{array}$ \\
\hline [4.3 years] & & Combination BP vs. standard control & $\begin{array}{l}\text { New or worsening nephropathy } \\
\text { New onset microalbuminuria }\end{array}$ & $\begin{array}{l}18 \% \\
21 \%\end{array}$ & $\begin{array}{c}0.6 \% \\
4 \%\end{array}$ & $\begin{array}{c}167 \\
25\end{array}$ & $\begin{array}{c}0.055 \\
<0.0001\end{array}$ \\
\hline $\begin{array}{l}\text { VADT }[14] \\
{[5.6 \text { years] }}\end{array}$ & 1,791 & Intensive vs. standard glycemic control & $\begin{array}{l}\text { Any increase in albuminuria } \\
\text { Progression to macroalbuminuria }\end{array}$ & $\begin{array}{l}34 \% \\
43 \%\end{array}$ & $\begin{array}{l}4.7 \% \\
2.2 \%\end{array}$ & $\begin{array}{l}21 \\
45\end{array}$ & $\begin{array}{l}0.03 \\
0.04\end{array}$ \\
\hline $\begin{array}{l}\text { UKPDS }^{*}[11,12] \\
\text { [Up to } 15 \text { years] }\end{array}$ & 3,867 & Intensive vs. standard glycemic control & Microalbuminuria & $30 \%$ at $15 \mathrm{yr}$ & $\begin{array}{c}11.9 \% \text { at } \\
15 \mathrm{yr}\end{array}$ & 8 & 0.033 \\
\hline [Up to 9 years] & 1,148 & Intensive vs. standard BP control & Urinary albumin $\geq 50 \mathrm{mg} / \mathrm{L}$ & $\begin{array}{l}29 \% \text { at } 6 \mathrm{yr} \\
13 \% \text { at } 9 \mathrm{yr}\end{array}$ & $\begin{array}{l}8.2 \% \text { at } 6 y r \\
4.3 \% \text { at } 9 y r\end{array}$ & $\begin{array}{l}12 \\
23\end{array}$ & $\begin{array}{c}0.0085 \\
0.33\end{array}$ \\
\hline
\end{tabular}

NNT number needed to treat = 1/absolute risk reduction; NR not reported; RR risk reduction; * UKPDS enrolled newly diagnosed type 2 diabetes patients; all other studies enrolled patients with longstanding type 2 diabetes; ACCORD Action to Control Cardiovascular Risk in Diabetes; ADVANCE Action in Diabetes and Vascular Disease: Preterax and Diamicron Modified Release Controlled Evaluation; ETDRS Early Treatment Diabetic Retinopathy Study; UKPDS United Kingdom Prospective Diabetes Study; VADT Veterans Affairs Diabetes Trial

Table 1: Effect of intensification of glucose or blood pressure control on progression of diabetic microvascular complications in type 2 diabetes patients, contd.

reduction [RRR] 37\%, p=0.003) (Table 1) [13]. Similar findings were reported by the Veterans Administration Diabetes Trial (VADT) [14], although the Action in Diabetes and Vascular disease: preterAx and diamicroN-MR Controlled Evaluation (ADVANCE) study showed no benefit $[14,15]$. Intensive glycemic control also favorably impacted certain intermediate renal outcomes, including new-onset microand macroalbuminuria in ACCORD, and new-onset or worsening albuminuria in ADVANCE and VADT, although the absolute benefit was less than that previously documented in newly-diagnosed patients in the UKPDS (Table 1) [12,14-16]. However, these findings need to be considered against the overall risks of glucose-lowering treatment. In ACCORD there was an increase in all-cause mortality in patients allocated to the intensive glucose-lowering arm [17]. More recently, the ORIGIN (Outcome Reduction with an Initial Glargine Intervention) study showed that early use of basal insulin to target normal fasting plasma glucose levels did not impact cardiovascular outcomes [18]. Both the ACCORD and ORIGIN studies also showed an increased risk of hypoglycemia and weight gain, detrimental for the management of patients with type 2 diabetes $[17,18]$. Furthermore, practical limitations relating to the likelihood of achieving normal or near-normal $\mathrm{HbA}_{1 \mathrm{c}}$ should not be understated. Taken together, the implications of these data are that targeting a near-normal $\mathrm{HbA}_{1 \mathrm{c}}$ value with currently available glucose-lowering therapies is not appropriate in high-risk patients with long-standing type 2 diabetes.

Improved blood pressure control was shown to reduce the development or progression of albuminuria in ADVANCE, although there was little benefit on diabetic retinopathy beyond that observed with conventional control [19] (Table 1). The ADVANCE retinal substudy showed a trend towards reduction in the risk of progression of retinopathy with combination blood pressure lowering treatment, although the difference versus standard therapy was not statistically significant (odds ratio $0.78,95 \%$ CI $0.57-1.06, \mathrm{p}=0.12$ ) [20].

Angiotensin-receptor blockade has shown class-specific benefits on microangiopathies. In the Renin-Angiotensin System Study (RASS), treatment with either enalapril or losartan reduced progression of diabetic retinopathy by $65 \%(\mathrm{p}=0.02)$ and $70 \%(\mathrm{p}=0.008)$, respectively [21]. Furthermore, in the DIRECT (Diabetic REtinopathy Candesartan Trials) program, treatment with candesartan reduced diabetic retinopathy in patients with type 1 diabetes (by 26\%, p=0.046) [22]. While there was evidence of regression of diabetic retinopathy in patients with type 2 diabetes, there was no significant benefit of treatment on retinal disease progression (the primary endpoint of the study) [22,23]. In addition, in the Randomized Olmesartan and Diabetes Microalbuminuria Prevention (ROADMAP) trial, olmesartan delayed the onset of microalbuminuria in type 2 diabetes patients with coronary artery disease and normoalbuminuria [24]. However, it should be noted that blood pressure control was similar in patients irrespective of the addition of olmesartan to conventional antihypertensive therapy, with $80 \%$ in the olmesartan group versus $71 \%$ of the placebo group achieving target blood pressure $(<130 / 80 \mathrm{mmHg})$. Furthermore, an excess of cardiovascular deaths in the olmesartan group was a concern. Thus, blood pressure lowering mediated via renin-angiotensin blockade is associated with renal protection in patients with type 2 diabetes, although the ACCORD blood pressure trial did suggest limitations with aggressive blood pressure lowering beyond that currently recommended by guidelines [25]. 
Citation: Hermans MP, Fruchart JC, Davignon J, Al-Rubeaan K, Amarenco P, et al. (2014) Residual Microvascular Risk in Type 2 Diabetes in 2014: Is it Time for a Re-Think? A Perspective from the Residual Risk Reduction Initiative (R3i). J Diabetes Metab 5: 413 doi:10.4172/21556156.1000413

Page 4 of 8

Finally, there is no evidence to date that further lowering of LDL cholesterol beyond desired levels benefits diabetic retinopathy [26]. Furthermore, the potential benefits of intensive LDL cholesterol lowering with high-dose statins need to be weighed against the known increase in risk of incident diabetes associated with this treatment, especially in patients with established risk factors for diabetes, or the potential to worsen glycemic control in patients already diagnosed with diabetes [27].

\section{A role for atherogenic dyslipidemia?}

Taken together, perhaps the main message from recent trials is to optimize control of conventional vascular risk factors to reduce the residual risk of diabetes-related microvascular complications. In this context, consideration of atherogenic dyslipidemia, the combination of elevated triglycerides - a marker of triglyceride-rich apolipoprotein B-containing lipoproteins - and low plasma concentration of HighDensity Lipoprotein (HDL) cholesterol may be relevant. The $\mathrm{R}^{3} \mathrm{i}$ has already highlighted atherogenic dyslipidemia as an important contributor to lipid-related residual macrovascular risk, and, potentially, to the risk of diabetic microvascular complications in persons receiving best standards of care for prevention of cardiovascular disease, including high-dose statins [8,28-30].

Recent studies provide a rationale for therapeutic targeting of atherogenic dyslipidemia. The Verona Diabetes Study a longitudinal, observational study in type 2 diabetes outpatients $(n=979)$, highlighted the relevance of the fasting triglycerides/HDL cholesterol ratio (TG/ HDL-C) to the risk of developing diabetic retinopathy or nephropathy [31]. Over a mean 4.9 year follow-up period, each one standard deviation increase in $\log$ TG/HDL-C more than doubled the risk of retinopathy and/or chronic kidney disease (odds ratio 2.15, 95\% CI 1.09-4.25, $\mathrm{p}=0.02)$; the increase in risk was even higher for chronic kidney disease alone (odds ratio $4.65,95 \%$ CI 1.50-14.90, $\mathrm{p}=0.02$ ). This association was independent of confounding factors including $\mathrm{HbA}_{1 \mathrm{c}}$, blood pressure, LDL cholesterol, albuminuria, diabetes duration and body mass index. The prognostic significance of an elevated $\log$ TG/HDL-C ratio was even more pronounced in patients with well controlled LDL cholesterol levels $(<100 \mathrm{mg} / \mathrm{dL})$. In a systematic review, elevated triglycerides were predictive of the onset or progression of nephropathy in patients with type 2 diabetes [32]. Additionally, post hoc analyses from ADVANCE highlighted low HDL cholesterol $(<43 \mathrm{mg} / \mathrm{dL})$ as a prognostic factor for the development of diabetic-related renal events, in particular newonset albuminuria [33]. There was, however, no association between low HDL cholesterol and risk for diabetic retinopathy. This is perhaps not surprising given the multiple pathways implicated in the underlying pathogenesis of this complication [34].

Most recently, the evidence-base for a role for atherogenic dyslipidemia has been strengthened by the REALIST (REsiduAl risk Lipids and Standard Therapies) microvascular study [35]. This crosssectional case-control study included 2,535 type 2 diabetes patients with either diabetic kidney disease $(n=1891)$, diabetic retinopathy $(n=1,218)$ or both complications $(n=574)$, and 3,683 matched controls, enrolled by 24 sites in 13 countries in Europe, North America, the Middle East, Asia (including Japan and China), and Australasia. REALIST-Micro showed that both elevated triglycerides and low HDL cholesterol were significantly and independently associated with diabetic microvascular complications, specifically diabetic kidney disease; the association was less robust for diabetic retinopathy. These associations persisted after adjustment for blood pressure and $\mathrm{HbA}_{1 c}$ (Table 2). Despite the limitations inherent with a cross-sectional design, heterogeneity with respect to lipid measurement across the centers and the potential for

\begin{tabular}{|l|c|}
\hline & Hazard ratio $(95 \% \mathrm{Cl})$ \\
\hline Any microvascular complication & \\
\hline Each $\uparrow$ by $44 \mathrm{mg} / \mathrm{dL}$ in TG & $1.16(1.11-1.22)$ \\
\hline Each $\uparrow 8 \mathrm{mg} / \mathrm{dL}$ in HDL-C & $0.92(0.88-0.96)$ \\
\hline Diabetic kidney disease & \\
\hline Each $\uparrow$ by $\sim 45 \mathrm{mg} / \mathrm{dL}$ in TG & $1.23(1.16-1.31)$ \\
\hline Each $\uparrow 8 \mathrm{mg} / \mathrm{dL}$ in HDL-C & $0.86(0.82-0.91)$ \\
\hline Retinopathy & \\
\hline Each $\uparrow$ by $\sim 45 \mathrm{mg} / \mathrm{dL}$ in TG & $1.09(1.02-1.16)^{\star}$ \\
\hline Each $\uparrow 8 \mathrm{mg} / \mathrm{dL}$ in HDL-C & $0.93(0.86-1.0)^{*}$ \\
\hline
\end{tabular}

Diabetic kidney disease was defined as either proteinuria $>300 \mathrm{mg} / \mathrm{L}$, albuminuria (albumin/creatinine ratio $\geq 30 \mu \mathrm{g} / \mathrm{mg}$ measured in a single morning urine sample; or $>20 \mu \mathrm{g} / \mathrm{min}$ in timed overnight urine collections; or $>30 \mathrm{mg} / 24 \mathrm{~h}$ in a 24 -hour urine), or estimated glomerular filtration rate $<60 \mathrm{ml} / \mathrm{min} / 1.73 \mathrm{~m}^{2}$, according to the Modification of Diet in Renal Disease formula. Retinopathy (including diabetic macular edema) was defined as laser treatment for diabetic retinopathy; Early Treatment Diabetic Retinopathy (ETDRS) staging $\geq 0$ on fundus photography; Diabetic Retinopathy Disease Severity Scale 3, 4 or 5 on dilated ophthalmoscopy, or moderate or severe maculopathy (Diabetic Macular Edema Disease Severity Scale).

Table 2: REALIST-Micro: association of triglycerides (TG) and HDL cholesterol with risk for diabetic kidney disease and/or diabetic retinopathy. Data from Sacks et al. [35].

reverse causation, this study is supportive of the rationale for targeting atherogenic dyslipidemia to reduce the residual diabetic renal disease risk.

There are so far limited data relating to the potential association between atherogenic dyslipidemia and diabetic neuropathy. A small study has implicated elevated triglycerides with diabetic neuropathy, a causative factor in lower-extremity amputations [36,37]. Hypertriglyceridemia was also an independent risk factor for lower extremity amputation in a large cohort of patients with diabetes $(\mathrm{n}=$ 28,701) within a US health claims database [38].

Taken together, the available data suggest a rationale for targeting atherogenic dyslipidemia, in addition to best standards of care, to reduce the residual risk of diabetic microvascular complications in patients with type 2 diabetes. Indeed, a recent observational cohort study of the US HealthCore Integrated Research Database $(n=72,267)$ provides evidence to support the value of targeting guideline-recommended levels for non-HDL cholesterol, HDL cholesterol and triglycerides in patients with newly-diagnosed type 2 diabetes. Compared with patients who did not meet these levels, those who attained desirable levels for HDL cholesterol $(>40 \mathrm{mg} / \mathrm{dL}$ for men and $>50 \mathrm{mg} / \mathrm{dL}$ for women) or triglycerides $(<150 \mathrm{mg} / \mathrm{dL})$ had an $11 \%$ and $15 \%$ lower risk, respectively, of diabetic microvascular events (diabetic neuropathy, retinopathy, and nephropathy, $\mathrm{p}<0.0001$ for each analysis) (Figure 2) [39]. However, due to the inherent limitations of this study design these findings should be viewed as hypothesis-generating and thus require testing in a randomized controlled trial.

\section{Reducing residual microvascular risk}

Clinical evidence for PPAR agonists: There is currently limited evidence for therapeutic strategies that reduce residual microvascular risk. The best evidence to date implicates a role for Peroxisome Proliferator Activated-Receptor (PPAR) agonists, with the most extensive data with fenofibrate, both for slowing progression of diabetic retinopathy and slowing progression of microalbuminuria (Table 3) [13,40-43]. Indeed, consistent evidence from two major prospective placebo-controlled studies - the Fenofibrate Intervention and Event 
Citation: Hermans MP, Fruchart JC, Davignon J, Al-Rubeaan K, Amarenco P, et al. (2014) Residual Microvascular Risk in Type 2 Diabetes in 2014 Is it Time for a Re-Think? A Perspective from the Residual Risk Reduction Initiative (R3i). J Diabetes Metab 5: 413 doi:10.4172/21556156.1000413

Lowering in Diabetes (FIELD) and ACCORD-Eye studies - that fenofibrate treatment delays progression of early diabetic retinopathy by $30-40 \%$ in type 2 diabetes patients with pre-existing disease, supported recent approval of fenofibrate as an adjunctive treatment to slow the progression of early-stage diabetic retinopathy in Australia (November, 2013). This clearly represents a major development for the management of diabetic eye disease. There are also data suggesting reduction in the risk of first minor lower-limb amputation associated with fenofibrate treatment in the FIELD study, although it is acknowledged that the etiology of diabetes-related amputation is complex, with neuropathy, macrovascular and microvascular disease all playing a role [44].

However, there remain a number of unanswered questions. First, are these effects specific to fenofibrate or do they relate to fibrates more generally? Indeed, findings from a recent study in a real-world setting ( $n=5,038$ type 2 diabetes patients) indicate that fibrate treatment (including bezafibrate, fenofibrate, ciprofibrate or gemfibrozil) was independently associated with reduction in progression to first retinopathy (primary outcome) [45]. Both bezafibrate $(n=1739)$ and fenofibrate $(\mathrm{n}=1413)$ were the most commonly prescribed fibrates in this study (for a mean of 2.1 and 2.8 years, respectively). However, with the limitations of a retrospective real-world data analysis, it is not possible to differentiate the effects of specific fibrates. Investigation of

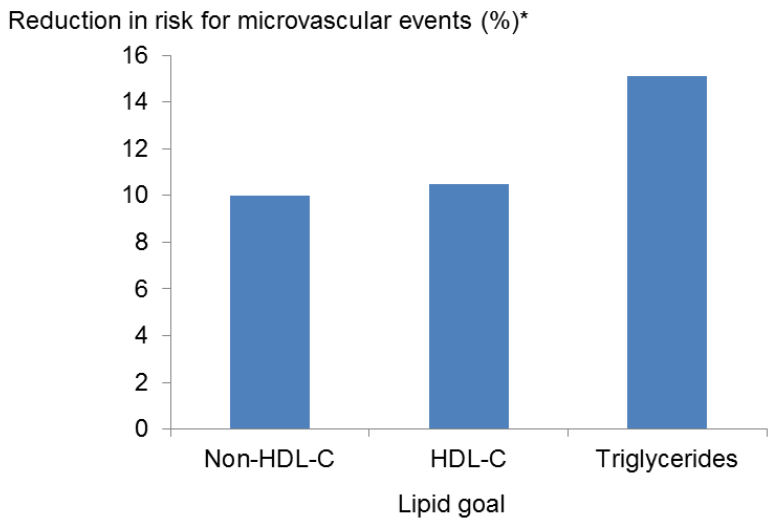

Figure 2: Lipid goal management and reduction in microvascular events in newly diagnosed type 2 diabetes patients $(n=72,267)$ in real-world setting.

Attainment of lipid goals for high-density lipoprotein (HDL) cholesterol, triglycerides and non-HDL cholesterol reduced the risk of diabetic complications (retinopathy, nephropathy or neuropathy, all $p<0.0001$ ). Data from Toth et al. [38]

* Adjusted multivariate Cox regression analysis for patients at lipid goal versus those who did not achieve lipid goal.

Lipid goals were defined according to the current American Diabetes Association guidelines; $\mathrm{HDL}$ cholesterol $>40 \mathrm{mg} / \mathrm{dL}$ in men and $>50 \mathrm{mg} / \mathrm{dL}$ in women and triglycerides $<150 \mathrm{mg} / \mathrm{dL}$. potential differential effects depending on the profile (alpha, gamma and/or delta), selectivity and potency of PPAR agonism at comparable doses is clearly warranted [46].

The other key question relates to the underlying mechanism(s), in particular for effects on diabetic retinopathy progression. While fibrates improve the underlying lipids and lipoproteins abnormalities associated with elevated triglycerides, decreased HDL number or functionality, and low plasma concentration of HDL cholesterol, the pathophysiological link between diabetic retinopathy and atherogenic dyslipidemia is tenuous. Indeed, in both the FIELD and ACCORD-Eye studies, there was no association between the lipoprotein- and lipidmodifying effects of fenofibrate and incidence or progression of diabetic retinopathy $[13,40,41]$. Recent insights suggest that both lipid-mediated as well as non-lipid mechanisms may be implicated [47]. These may include systemic effects mediated by upregulation of apolipoprotein A-I (apoA-I, the main apolipoprotein in HDL), as suggested by small, single center studies, as well as local or systemic changes influencing intraretinal lipid transport $[48,49]$. Furthermore, whether effects on the qualitative properties of lipoproteins play a role is not known, although it is likely that the recognized pleiotropic effects of fibrates, including antioxidant, anti-inflammatory and anti-apoptotic properties, and improvement of endothelial function are perhaps more relevant, as previously discussed by Simo et al. [47].

As with all treatments, risk versus benefit considerations is merited. Fenofibrate is known to increase serum creatinine, which may prompt questions about its wider use in type 2 diabetes patients who often have some degree of renal impairment. In ACCORD Lipid, an increase in serum creatinine (defined as $\geq 20 \%$ increase from pre-treatment levels) was reported for nearly one-half $(48 \%)$ of patients with longstanding type 2 diabetes within 3 months of starting fenofibrate treatment (versus $9 \%$ of the placebo group). Of these patients, about one-quarter subsequently received a reduced dose of fenofibrate, and about one-third stopped study treatment [50]. However, in both the FIELD and ACCORD Lipid studies the increase in serum creatinine was transient and reversible within 6-8 weeks $[40,51,52]$. Furthermore, subsequent analyses showed that the increase in serum creatinine in fenofibrate-treated patients was unexpectedly associated with slower (rather than higher) secular loss of renal function. Over the course of the 5-year follow-up in the FIELD study, the decline in estimated glomerular filtration rate (eGFR) was reduced by $73 \%$ with fenofibrate compared with placebo [51]. Additionally, in the Renal Ancillary study of ACCORD Lipid, among patients in the fenofibrate treatment group who were chosen because they did not show any increase in serum creatinine ( $\leq 2 \%$ change from pre-treatment levels), mean eGFR at the end of study was higher compared with those in the placebo group ( 81.8 versus $77.8 \mathrm{~mL} / \mathrm{min} / 1.73 \mathrm{~m}^{2}$ ), raising the possibility that there was net preservation of renal function over time in this group [52]. Further,

\begin{tabular}{|c|c|c|c|c|c|}
\hline Study & Microvascular outcome & Relative RR & Absolute RR & NNT & p-value \\
\hline $\begin{array}{l}\text { FIELD [41] } \\
{[\mathrm{N}=9,795]}\end{array}$ & First laser treatment for retinopathy & $31 \%$ & $1.5 \%$ & 67 & 0.002 \\
\hline $\begin{array}{l}\text { FIELD substudy [41] } \\
{[\mathrm{N}=1,012]}\end{array}$ & $\begin{array}{l}\text { i) DR progression, i.e. } \geq 2 \text { steps of the ETDRS, macular edema or laser treatment } \\
\text { ii) } \geq 2 \text { steps of the ETDRS } \\
\text { All patients } \\
\text { Pre-existing retinopathy } \\
\text { No pre-existing retinopathy }\end{array}$ & $\begin{array}{l}31 \% \\
22 \% \\
79 \% \\
2.6 \%\end{array}$ & $\begin{array}{l}5.0 \% \\
\\
2.7 \% \\
11.5 \% \\
0.3 \%\end{array}$ & $\begin{array}{c}20 \\
37 \\
9 \\
333\end{array}$ & $\begin{array}{l}0.022 \\
0.19 \\
0.004^{*} \\
0.87^{*}\end{array}$ \\
\hline $\begin{array}{l}\text { ACCORD-EYE }[3] \\
{[N=1,593]}\end{array}$ & $\begin{array}{l}\text { DR progression, i.e. } \geq 3 \text { steps of the ETDRS or proliferative DR requiring laser } \\
\text { therapy or vitrectomy }\end{array}$ & $40 \%$ & $3.7 \%$ & 27 & 0.006 \\
\hline
\end{tabular}

*treatment versus retinopathy status interaction, $p=0.019$; NNT number needed to treat $=1$ /absolute risk reduction; RR risk reduction; ETDRS Early Treatment Diabetic Retinopathy Study scale; FIELD: Fenofibrate Intervention and Event Lowering in Diabetes; ACCORD: Action to Control Cardiovascular Risk in Diabetes

Table 3: Effects of fenofibrate on Diabetic Retinopathy (DR) progression: Summary of results from the FIELD and ACCORD-Eye studies [13,41]. 
Citation: Hermans MP, Fruchart JC, Davignon J, Al-Rubeaan K, Amarenco P, et al. (2014) Residual Microvascular Risk in Type 2 Diabetes in 2014 Is it Time for a Re-Think? A Perspective from the Residual Risk Reduction Initiative (R3i). J Diabetes Metab 5: 413 doi:10.4172/21556156.1000413

the fenofibrate-associated increase in serum creatinine did not appear to detrimentally impact cardiovascular risk, as indicated by a post hoc subgroup analysis of the FIELD study. While patients in the placebo group of this study with moderate renal impairment had the highest cardiovascular event rates, fenofibrate treatment was associated with a relative reduction in cardiovascular risk of $32 \%$ versus $15 \%$ in patients with normal renal function [53]. Admittedly, this analysis was based on a limited sample ( $\sim 5 \%$ of the total study population), and the use of the Modification of Diet in Renal Disease formula in FIELD may have underestimated eGFR. Despite these caveats, these data may help to reassure clinicians who may be considering the use of adjunctive fenofibrate therapy in type 2 diabetes patients.

Evidence for other approaches: Evidence for other therapeutic approaches is limited. There may be a rationale for investigating the potential of omega-3 fatty acids, given experimental data showing favorable effects on key mechanisms implicated in the vasodegenerative phase of diabetic retinopathy, and preservation of retinal function in animal models of type 2 diabetes mellitus [54,55]. Additionally, expression of GPR109A, a niacin receptor, which has anti-inflammatory activity in the retinal pigment epithelium, is increased in diabetic mouse and human retinas, which might suggest therapeutic potential [56]. However, there are as yet no clinical data to support these hypotheses. Novel approaches are also warranted.

\section{Conclusion}

\section{$R^{3}$ i recommendations}

The $\mathrm{R}^{3} \mathrm{i}$ believe that optimizing the control of cardiovascular risk factors is critical to reducing the residual risk of diabetes-related microvascular complications in patients with type 2 diabetes. In this context, management of atherogenic dyslipidemia, a key driver of cardiovascular risk in this patient group, in addition to best standards of care, is relevant as supported by evidence from the REALIST-Micro study [35].In support, a large-scale study in a real-life setting suggested that improved lipid management, targeting HDL cholesterol and triglycerides in addition to non-HDL cholesterol, can reduce the risk of diabetic retinopathy, peripheral neuropathy, and/or nephropathy in type 2 diabetes patients [39]. These data reinforce the importance of achieving appropriate lipid and lipoprotein levels as a key tenet of management to reduce both macro- and microvascular residual risk in patients with type 2 diabetes.

In terms of therapeutic targeting to reduce residual microvascular risk, the available data support a role for PPAR agonism, with the strongest evidence to date for fenofibrate, for slowing progression of early-stage diabetic retinopathy in patients with type 2 diabetes mellitus, as well as slowing progression of albuminuria. However, there remain unanswered questions as to the underlying mode of action, with both lipid- and non-lipid-related mechanisms implicated [46]. Whether there are differential effects depending on the profile (alpha, gamma and/or delta), selectivity and potency of PPAR agonism clearly merits further investigation. Finally, whether the favorable microvascular benefits of PPAR $\alpha$ agonism observed with fenofibrate extend to type 1 diabetes, a condition often characterized by lifelong hyperglycemia exposure, remains an open question.

Globally, we are facing a tsunami of type 2 diabetes, with prevalence estimates continually revised upwards. A major burden of diabetes lies in its chronic complications, both cardiovascular and microvascular. However, microvascular complications associated with type 2 diabetes are expected to account for much of the societal burden of disease,
- Improved management of cardiometabolic risk factors. Attainment of all lipid goals, including non-HDL cholesterol and apolipoprotein B, and desirable levels for HDL cholesterol and triglycerides, is essential.

- Consistent evidence from two major prospective trials may merit consideration by clinicians of adjunctive fenofibrate therapy to slow progression of diabetic retinopathy in type 2 diabetes patients. These data provide a strong rationale for testing this in a major prospective study.

Table 4: Recommendations of the R3i to reduce the residual risk of diabetesrelated microvascular complications in patients with type 2 diabetes.

with progression to more advanced stages substantially increasing costs and disability and detrimentally affecting patient quality of life. This scenario highlights an urgent need for a renewed focus on approaches to prevent or delay progression of diabetic microvascular complications that occur despite best current standards of care.

The $\mathrm{R}^{3} \mathrm{i}$ believes that there are two key priorities to reducing the residual risk of diabetic complications in type 2 diabetes (Table 4). First, there is a need for optimal management of cardiometabolic risk factors, including atherogenic dyslipidemia, with improved lipid goal attainment. Second, the $\mathrm{R}^{3} \mathrm{i}$ believes that the consistent evidence for fenofibrate from the FIELD and ACCORD-Eye studies may merit consideration by clinicians involved in the care of patients with type 2 diabetes and retinopathy. The $\mathrm{R}^{3} \mathrm{i}$ believes that these data provide a clear rationale for a major prospective trial to investigate the role of fenofibrate, adjunctive to best standards of care, in preventing or slowing diabetic retinopathy in patients with type 2 diabetes. Collaboration between primary and secondary healthcare personnel on screening and preventive strategies targeted to the earliest stages of diabetic microvascular complications, in particular diabetic retinopathy, will help to drive through improvements in patient care. In conclusion, the $\mathrm{R}^{3} \mathrm{i}$ strongly believes that addressing both priorities is essential to reducing the substantial, disabling socioeconomic burden associated with the residual risk of diabetes-related chronic microvascular complications in type 2 diabetes.

\section{Authors' Contribution}

MPH, JD and JCF researched data and prepared the initial draft manuscript. All authors were involved in the review of the manuscript and all approved the final manuscript. MPH takes responsibility for the content of the article.

\section{Acknowledgements}

Funding

The R3i is a non-profit academic organization which currently receives unrestricted educational grants from Abbott, Kowa and Roche. These grantors had no role in the design, preparation or review of this manuscript.

\section{Conflicts of interest}

P Amarenco (PA) has received research grants from Pfizer, Sanofi, BristolMyers-Squibb, Merck, AstraZeneca, Boehringer Ingelheim and the French government; and honoraria for lectures/consultancy from Pfizer, Sanofi, BristolMyers-Squibb, Merck, AstraZeneca, Boehringer Ingelheim, Bayer, Daiichi Sankyo, Lundbeck, Edwards, Boston Scientific, Kowa, and St-Jude Medical.

$\mathrm{P}$ Barter (PB) has received research grants from Merck and Pfizer; honoraria for consulting from Amgen, AstraZeneca, ISIS, Kowa, Merck, Novartis, Pfizer and Roche; and honoraria as a member of Advisory Boards from AstraZeneca, CSL, Kowa, Lilly, Merck, Novartis, Pfizer and Roche.

$\mathrm{J}$ Betteridge (JB) has received honoraria for advisory boards and lectures from MSD, Pfizer, AstraZeneca, Kowa, Janssen, Amgen, Takeda and Sanofi.

E Bruckert (EB) has received research funding from GlaxoSmithKline, MSD Genzyme, Sanofi, Aegerion and Montreal University; and honoraria for consulting/ presentation from AstraZeneca, Genfit, Genzyme, MSD, Pfizer, Sanofi, Servier, AMT, Merck, Lilly, Novo-Nordisk, Pfizer and Aegerion. 
Citation: Hermans MP, Fruchart JC, Davignon J, Al-Rubeaan K, Amarenco P, et al. (2014) Residual Microvascular Risk in Type 2 Diabetes in 2014 Is it Time for a Re-Think? A Perspective from the Residual Risk Reduction Initiative (R3i). J Diabetes Metab 5: 413 doi:10.4172/21556156.1000413

MJ Chapman has received lecture honoraria, consultancy fees, or research funding from Aegerion, Amgen, AstraZeneca, Danone, Genzyme, Hoffman-La Roche, Kowa, Merck/Schering Plough, Pfi zer, Sanofi -Aventis/Regeneron, and Unilever.

A Cuevas (AC) has served on advisory boards for MSD and Amgen, and has received honoraria for lectures from MSD and Sanofi.

$\mathrm{J}$ Davignon (JD) has received honoraria for consultancy or as a scientific advisor for Abbott (Solvay), Acasti Pharma, Amgen, AstraZeneca, Anthera Genzyme, McCain, Merck, Pfizer, Pharmena (Cortria), Regeneron-Sanofi, Roche and Valeant; and for participation in clinical trials for Amgen, Cortria, Genzyme, Merck, Pfizer and Regeneron-Sanofi. He has also received honoraria as a member of the Speakers bureau for the International Atherosclerosis Society. He is a Board Member for the Consortium Québecois sur la Découverte du Médicament (CQDM), and the Residual Risk Reduction Initiative Foundation.

E Ferrannini (EF) has received honoraria for speakers bureau/advisory boards from MDS, Halozyme, GlaxoSmithKline, Bristol-Myers-Squibb /AstraZeneca, El Lilly \& Co., Novartis, Daiichi Sankyo and Sanofi. He has received research gran support from Eli Lilly \& Co and Boehringer Ingelheim.

M Farnier (MF) has received grants, consulting fees and/or honoraria for lectures for Abbott, Amgen, Boehringer Ingelheim, Genzyme, Kowa, Merck and Co., Novartis, Pfizer, Recordati, Roche, Sanofi-Aventis and Bristol-Myers-Squibb.

P Fioretto (PF) has received honoraria for lectures from Abbott, Bristol-MyersSquibb, AstraZeneca, Boehringer and Lilly.

J-C Fruchart (JCF) has received honoraria as a consultant for SMB laboratories, McCain and Kowa Co. Ltd. He is President of the Residual Risk Reduction Initiative.

J Genest (JG) has received research funding from Amgen, Lilly and Merck and honoraria as a member of Speaker's bureau/advisory boards from Merck, Amgen, Sanofi and Aegerion.

HN Ginsberg (HNG) has received research funds from Sanofi-Regeneron, Amgen, Sanofi-Genzyme, Merck and consulting honoraria from Sanofi-Regeneron, Amgen, Sanofi-Genzyme, Merck, Bristol-Myers-Squibb, AstraZeneca, Pfizer, Kowa, Janssen and Boehringer Ingelheim.

AM Gotto (AMG) is on the board of Directors for Aegerion and Arisaph; has been a consultant for AstraZeneca, Janssen, Kowa, Merck, Pfizer and Roche; and has served on advisory boards for DuPont and Vatera Capital.

MP Hermans (MPH) has served on an advisory panel and/or received speaker's honoraria or travel/research grants from Abbott, Amgen, AstraZeneca, Boehringer Bristol-Myers-Squibb, Boehringer Ingelheim, GlaxoSmithKline, Janssen, Eli Lilly, LifeScan, Menarini, Merck, Novartis, Novo Nordisk, Roche, Sanofi and Takeda.

T Kodama (TK) has received honoraria as a consultant for Kowa Co.Ltd. and received research funding from Kowa Co. Ltd

M Krempf (MK) has received honoraria for lectures from Astra Zeneca, MSD, Bristol-Myers-Squibb and Sanofi.

$\mathrm{J}$ Millan Nuñez-Cortes (JMN-C) has received honoraria as a member of Advisory Boards from Abbott, AstraZeneca, MSD, Pfizer and Sanofi; and for educational activities from Abbott, AstraZeneca and MSD.

$\mathrm{H}$ Ogawa $(\mathrm{HO})$ has received honoraria for consulting from Amgen, GlaxoSmithKline and Novartis; and honoraria for lectures from AstraZeneca, Bayer Boehringer Ingelheim, Daiichi Sankyo, Mitsubishi Tanabe, MSD, Pfizer, Sanofi and Takeda. He has received research/scholarship grants from Bayer, Daiichi Sankyo, AstraZeneca, Astellas, Takeda, Mitsubishi Tanabe, Boehringer Ingelheim, MSD and Pfizer.

J Plutzky (JP) has received research grants from GlaxoSmithKline and Bristol-Myers-Squibb; and honoraria for consultancy from Amylin Pharmaceuticals, AstraZeneca, Bristol-Myers-Squibb, Genzyme, GlaxoSmithKline, Eli Lilly, Janssen, Mesoblast, Merck, NovoNordisk, Pfizer, Roche/Genentech, Takeda and Vivus.

D Rader (DR) has received honoraria for consulting from Merck, Pfizer, Eli Lilly, Sanofi, Amgen, Novartis, Omthera, Aegerion and CSL.

$\mathrm{Z}$ Reiner (ZR) has received honoraria for lectures and advisory boards from Abbott, AstraZeneca and Sanofi.

$\mathrm{R}$ Santos (RS) has received honoraria for consulting and/or speaking from Astra Zeneca, Abbott, Biolab, Merck, Bristol Myers Squibb, Roche, Pfizer, Amgen Aegerion, Boehringer Ingelheim, Sanofi, Genzyme and Nestle.

A Tall (AT) has received honoraria for lectures and advisory boards from MSD, Eli Lilly, Roche, Amgen, Arisaph and CSL.
Tokgozoglu (LT) has received honoraria for lectures and advisory boards from Abbott, Actelion, AstraZeneca, Bayer, Boehringer Ingelheim, Daiichi Sankyo, Kowa, MSD, Novartis, Pfizer, Roche, Sanofi and Servier.

PP Toth (PPT) has received honoraria as a member of Speakers bureau for Amarin, AstraZeneca, GlaxoSmithKline, Kowa, Merck; and for consultancy for Amgen, AstraZeneca, Atherotech, Boehringer Ingelheim, Kowa, Liposcience and Merck.

P Valensi (PV) has given lectures and/or been a consultant for Abbott, MSD and Kowa.

C Wanner (CW) has received honoraria for lectures and travel support from Astellas, Merck and Pfizer.

A Zambon (AZ) has received speaker honoraria from Abbott, AstraZeneca, Roche and Amgen.

$\mathrm{P}$ Zimmet (PZ) has received travel funding from Fournier.

K Al-Rubeaan (KA-R), G Assmann (GA), Y Matsuzawa (YM), C Calvo Monfil (CCM), D Hu (DH), T Kadowaki (TK), S Sadikot (SS), E Shlyakhto (ES), P Sritara (PS), R Sy (RS), CE Tan (CET) and JR Zhu (JRZ) report no competing interests.

\section{References}

1. International Diabetes Federation (2013) IDF Atlas Sixth Edition. Accessed 19 May 2014.

2. Lim SS, Vos T, Flaxman AD, Danaei G, Shibuya K, et al. (2012) A comparative risk assessment of burden of disease and injury attributable to 67 risk factors and risk factor clusters in 21 regions, 1990-2010: a systematic analysis for the Global Burden of Disease Study 2010. Lancet 380: 2224-2260.

3. Cheung N, Mitchell P, Wong TY (2010) Diabetic retinopathy. Lancet 376: 124 136.

4. Bongaerts BW, Rathmann W, Heier M, Kowall B, Herder C, et al. (2013) Older subjects with diabetes and prediabetes are frequently unaware of having distal sensorimotor polyneuropathy: the KORA F4 study. Diabetes Care 36: 11411146.

5. Pelletier EM, Shim B, Ben-Joseph R, Caro JJ (2009) Economic outcomes associated with microvascular complications of type 2 diabetes mellitus: results from a US claims data analysis. Pharmacoeconomics 27: 479-490.

6. Lind M, Garcia-Rodriguez LA, Booth GL, Cea-Soriano L, Shah BR, et al. (2013) Mortality trends in patients with and without diabetes in Ontario, Canada and the UK from 1996 to 2009: a population-based study. Diabetologia 56: 26012608 .

7. American Diabetes Association (2013) Economic costs of diabetes in the U.S in 2012. Diabetes Care 36: 1033-1046.

8. Fruchart JC, Sacks FM, Hermans MP, Assmann G, Brown WV, et al. (2008) The Residual Risk Reduction Initiative: a call to action to reduce residual vascular risk in dyslipidaemic patient. Diab Vasc Dis Res 5: 319-335.

9. Gaede P, Vedel P, Larsen N, Jensen GV, Parving HH, et al. (2003) Multifactorial intervention and cardiovascular disease in patients with type 2 diabetes. N Eng J Med 348: 383-393.

10. Gaede P, Lund-Andersen H, Parving HH, Pedersen O (2008) Effect of multifactorial intervention on mortality in type 2 diabetes. N Engl J Med 358: 580-591.

11. [No authors listed] (1998) Intensive blood-glucose control with sulphonylureas or insulin compared with conventional treatment and risk of complications in patients with type 2 diabetes (UKPDS 33). UK Prospective Diabetes Study (UKPDS) Group. Lancet 352: 837-853.

12. United Kingdom Prospective Diabetes Study Group (1998) Tight blood pressure control and risk of macrovascular and microvascular complications in type 2 diabetes: UKPDS 38. BMJ 317: 703-713.

13. ACCORD Study Group; ACCORD Eye Study Group, Chew EY, Ambrosius WT, Davis MD, Danis RP, et al. (2010) Effects of medical therapies on retinopathy progression in type 2 diabetes. N Engl J Med 363: 233-244.

14. Duckworth W, Abraira C, Moritz T, Reda D, Emanuele N, et al. (2009) Glucose control and vascular complications in veterans with type 2 diabetes. $\mathrm{N}$ Engl J Med 360: 129-139.

15. ADVANCE Collaborative Group, Patel A, MacMahon S, Chalmers J, Neal B, et al. (2008) Intensive blood glucose control and vascular outcomes in patients with type 2 diabetes. N Engl J Med 358: 2560-2572. 
Citation: Hermans MP, Fruchart JC, Davignon J, Al-Rubeaan K, Amarenco P, et al. (2014) Residual Microvascular Risk in Type 2 Diabetes in 2014 Is it Time for a Re-Think? A Perspective from the Residual Risk Reduction Initiative (R3i). J Diabetes Metab 5: 413 doi:10.4172/21556156.1000413

16. Ismail-Beigi F, Craven T, Banerii MA, Basile J, Calles J, et al. (2010) Effect of intensive treatment of hyperglycaemia on microvascular outcomes in type 2 diabetes: an analysis of the ACCORD randomised trial. Lancet 376: 419-430.

17. Action to Control Cardiovascular Risk in Diabetes Study Group, Gerstein HC Miller ME, Byington RP, Goff DC Jr, et al. (2008) Effects of intensive glucose lowering in type 2 diabetes. N Engl J Med 358: 2545-2559.

18. ORIGIN Trial Investigators, Gerstein HC, Bosch J, Dagenais GR, Díaz R, et al. (2012) Basal insulin and cardiovascular and other outcomes in dysglycemia. N Engl J Med 367: 319-328.

19. Patel A; ADVANCE Collaborative Group, MacMahon S, Chalmers J, Neal B Woodward M, et al. (2007) Effects of a fixed combination of perindopril and indapamide on macrovascular and microvascular outcomes in patients with type 2 diabetes mellitus (the ADVANCE trial): a randomised controlled trial. Lancet 370: 829-824.

20. Beulens JW, Patel A, Vingerling JR, Cruickshank JK, Hughes AD, et al (2009) Effects of blood pressure lowering and intensive glucose control on the incidence and progression of retinopathy in patients with type 2 diabetes mellitus: a randomised controlled trial. Diabetologia 52: 2027-2036.

21. Mauer M, Zinman B, Gardiner R, Suissa S, Sinaiko A, et al. (2009) Renal and retinal effects of enalapril and losartan in type 1 diabetes. $\mathrm{N}$ Engl $\mathrm{J}$ Med 361 : 40-51.

22. Chaturvedi N, Porta M, Klein R, Orchard T, Fuller J, et al. (2008) Effect of candesartan on prevention (DIRECT-Prevent1) and progression (DIRECTProtect1) of retinopathy in type 1 diabetes: randomised, placebo-controlled trials. Lancet 372: 1394-1402.

23. Sjølie AK, Klein R, Porta M, Orchard T, Fuller J, et al. (2008) Effect of candesartan on progression and regression of retinopathy in type 2 diabetes (DIRECT-Protect 2): a randomised placebo-controlled trial. Lancet 372: 13851393.

24. Haller H, Ito S, Izzo JL Jr, Januszewicz A, Katayama S, et al. (2011) Olmesartan for the delay or prevention of microalbuminuria in type 2 diabetes. $\mathrm{N}$ Engl $\mathrm{J} \mathrm{Med}$ 364: 907-917.

25. ACCORD Study Group, Cushman WC, Evans GW, Byington RP, Goff DC Jr, et al. (2010) Effects of intensive blood-pressure control in type 2 diabetes mellitus. N Engl J Med 362: 1575-1585.

26. Lim LS, Wong TY (2012) Lipids and diabetic retinopathy. Expert Opin Biol Ther 12: 93-105.

27. Sattar N, Preiss D, Murray HM, Welsh P, Buckley BM, et al. (2010) Statins and risk of incident diabetes: a collaborative meta-analysis of randomised statin trials. Lancet 375: 735-742.

28. Fioretto P, Dodson PM, Ziegler D, Rosenson RS (2010) Residual microvascular risk in diabetes: unmet needs and future directions. Nat Rev Endocrinol 6: 19-25.

29. Fruchart JC, Davignon J, Hermans MP, Al-Rubeaan K, Amarenco P, et al. (2014) Residual macrovascular risk in 2013: what have we learned? Cardiovasc Diabetol 13: 26.

30. Reiner Ž (2013) Managing the residual cardiovascular disease risk associated with HDL-cholesterol and triglycerides in statin-treated patients: A clinical update. Nutr Metab Cardiovasc Dis 23: 799-807.

31. Zoppini G, Negri C, Stoico V, Casati S, Pichiri I, et al. (2012) Triglyceride-highdensity lipoprotein cholesterol is associated with microvascular complications in type 2 diabetes mellitus. Metabolism 61: 22-29.

32. Hellemons ME, Kerschbaum J, Bakker SJ, Neuwirt H, Mayer B, et al. (2012) Validity of biomarkers predicting onset or progression of nephropathy in patients with Type 2 diabetes: a systematic review. Diabet Med 29: 567-577.

33. Morton J, Zoungas S, Li Q, Patel AA, Chalmers J, et al. (2012) Low HDL cholesterol and the risk of diabetic nephropathy and retinopathy: results of the ADVANCE study. Diabetes Care 35: 2201-2206.

34. Antonetti DA, Klein R, Gardner TW (2012) Diabetic retinopathy. N Engl J Med 366: 1227-1239.

35. Sacks FM, Hermans MP, Fioretto P, Valensi P, Davis T, et al. (2014) Association between plasma triglycerides and HDL-cholesterol and microvascular kidney disease and retinopathy in type 2 diabetes: A global case-control study in 13 countries. Circulation 129: 999-1008.

36. Wiggin TD, Sullivan KA, Pop-Busui R, Amato A, Sima AA, et al. (2009) Elevated triglycerides correlate with progression of diabetic neuropathy. Diabetes 58 1634-1640.
37. Malik RA, Tesfaye S, Ziegler D (2013) Medical strategies to reduce amputation in patients with type 2 diabetes. Diabet Med 30: 893-900.

38. Callaghan BC, Feldman E, Liu J, Kerber K, Pop-Busui R, et al. (2011) Triglycerides and amputation risk in patients with diabetes: ten-year follow-up in the DISTANCE study. Diabetes Care 34: 635-640.

39. Toth PP, Simko RJ, Palli SR, Koselleck D, Quimbo RA, et al. (2012) The impact of serum lipids on risk for microangiopathy in patients with type 2 diabetes mellitus. Cardiovasc Diabetol 11: 109

40. Keech A, Simes RJ, Barter P, Best J, Scott R, et al. (2005) Effect of longterm fenofibrate therapy on cardiovascular events in 9795 people with type 2 diabetes mellitus (the FIELD study): randomised controlled trial. Lancet 366 1849-1861.

41. Keech AC, Mitchell P, Summanen PA, O'Day J, Davis TM, et al. (2007) Effect of fenofibrate on the need for laser treatment for diabetic retinopathy (FIELD study): a randomised controlled trial. Lancet 370: 1687-1697.

42. Ansquer JC, Foucher C, Rattier S, Taskinen MR, Steiner G, et al. (2005) Fenofibrate reduces progression to microalbuminuria over 3 years in a placebocontrolled study in type 2 diabetes: results from the Diabetes Atherosclerosis Intervention Study (DAIS). Am J Kidney Dis 45: 485-493.

43. ACCORD Study Group, Ginsberg HN, Elam MB, Lovato LC, Crouse JR 3rd et al. (2010) Effects of combination lipid therapy in type 2 diabetes mellitus. N Engl J Med 362: 1563-1574.

44. Rajamani K, Colman PG, Li LP, Best JD, Voysey M, et al. (2009) Effect of fenofibrate on amputation events in people with type 2 diabetes mellitus (FIELD study): a prespecified analysis of a randomised controlled trial. Lancet 373 1780-1788.

45. Morgan CL, Owens DR, Aubonnet P, Carr ES, Jenkins-Jones S, et al. (2013) Primary prevention of diabetic retinopathy with fibrates: a retrospective, matched cohort study. BMJ Open 3: e004025.

46. Fruchart JC (2013) Selective peroxisome proliferator-activated receptor $\hat{I} \pm$ modulators (SPPARMÎt): the next generation of peroxisome proliferatoractivated receptor Ît-agonists. Cardiovasc Diabetol 12: 82

47. Simó R, Roy S, Behar-Cohen F, Keech A, Mitchell P, et al. (2013) Fenofibrate: a new treatment for diabetic retinopathy. Molecular mechanisms and future perspectives. Curr Med Chem 20: 3258-3266.

48. Sasongko MB, Wong TY, Nguyen TT, Shaw JE, Jenkins AJ, et al. (2012) Nove versus traditional risk markers for diabetic retinopathy. Diabetologia 55: 666670

49. Simó R, García-Ramírez M, Higuera M, Hernández C (2009) Apolipoprotein A1 is overexpressed in the retina of diabetic patients. Am J Ophthalmol 147: 319-325.

50. Bonds DE, Craven TE, Buse J, Crouse JR, Cuddihy R, et al. (2012) Fenofibrateassociated changes in renal function and relationship to clinical outcomes among individuals with type 2 diabetes: the Action to Control Cardiovascular Risk in Diabetes (ACCORD) experience. Diabetologia 55: 1641-1650.

51. Davis TM, Ting R, Best JD, Donoghoe MW, Drury PL, et al. (2011) Effects of fenofibrate on renal function in patients with type 2 diabetes mellitus: the Fenofibrate Intervention and Event Lowering in Diabetes (FIELD) Study. Diabetologia 54: 280-290.

52. Mychaleckyj JC, Craven T, Nayak U, Buse J, Crouse JR, et al. (2012) Reversibility of fenofibrate therapy-induced renal function impairment in ACCORD type 2 diabetic participants. Diabetes Care 35: 1008-1014.

53. Ting RD, Keech AC, Drury PL, Donoghoe MW, Hedley J, et al. (2012) Benefits and safety of long-term fenofibrate therapy in people with type 2 diabetes and renal impairment: the FIELD Study. Diabetes Care 35: 218-225.

54. Tikhonenko M, Lydic TA, Opreanu M, Li Calzi S, Bozack S, et al. (2013) N-3 polyunsaturated Fatty acids prevent diabetic retinopathy by inhibition of retinal vascular damage and enhanced endothelial progenitor cell reparative function. PLoS One 8: e55177.

55. Sapieha P, Chen J, Stahl A, Seaward MR, Favazza TL, et al. (2012) Omega-3 polyunsaturated fatty acids preserve retinal function in type 2 diabetic mice. Nutr Diabetes 2: e36.

56. Gambhir D, Ananth S, Veeranan-Karmegam R, Elangovan S, Hester S, et al. (2012) GPR109A as an anti-inflammatory receptor in retinal pigment epithelia cells and its relevance to diabetic retinopathy. Invest Ophthalmol Vis Sci 53 2208-2217. 